\title{
Congenital Hypothyroid Goiter with Deficient Thyroglobulin Identification of an Endoplasmic Reticulum Storage Disease with Induction of Molecular Chaperones
}

\author{
Geraldo Medeiros-Neto, ${ }^{\star}$ Paul S. Kim,, Sung E. Yoo,, Jussara Vono,‡ Hector M. Targovnik, ${ }^{\star}$ Rosalinda Camargo, \\ S. Abu Hossain, ${ }^{\ddagger}$ and Peter Arvan ${ }^{\ddagger \S}$ \\ *Thyroid Unit, Division of Endocrinology, University of Sao Paulo Medical School, Sao Paulo, Brazil; ${ }^{*}$ Division of Endocrinology, Beth \\ Israel Hospital, Harvard Medical School, Boston, Massachusetts 02215; and ${ }^{\S}$ Program in Biological and Biomedical Sciences, Harvard \\ Medical School, Boston, Massachusetts 02215
}

\begin{abstract}
Recent advances in understanding the molecular pathogenesis of congenital hypothyroid goiter in $\operatorname{cog} / \operatorname{cog}$ mice, have raised important questions concerning the maturation of thyroglobulin (the thyroid prohormone) in certain human kindreds with congenital goiter. We have now examined affected siblings from two unrelated families that synthesize an apparently normally glycosylated, $>300 \mathrm{kD}$ immunoreactive thyroglobulin, yet have a reduced quantity of intraglandular thyroglobulin and that secreted into the circulation. From thyroid tissues of the four patients, light microscopic approaches demonstrated presence of intracellular thyroglobulin despite its absence in thyroid follicle lumina, while electron microscopy indicated abnormal distention of the endoplasmic reticulum (ER). We have confirmed biochemically that most intrathyroidal thyroglobulin fails to reach the (Golgi) compartment where complex carbohydrate modification takes place. Moreover, the disease in the affected patients is associated with massive induction of specific ER molecular chaperones including the hsp90 homolog, GRP94, and the hsp70 homolog, BiP. The data suggest that these patients synthesize a mutant thyroglobulin which is defective for folding/assembly, leading to a markedly reduced ability to export the protein from the ER. Thus, these kindreds suffer from a thyroid ER storage disease, a cell biological defect phenotypically indistinguishable from that found in $\operatorname{cog} / \mathrm{cog}$ mice. (J. Clin. Invest. 1996. 98:2838-2844.) Key words: thyroid - protein folding • GRP94 • BiP • intracellular transport
\end{abstract}

\section{Introduction}

Mutations in secretory or plasma membrane proteins are one important cause of endoplasmic reticulum storage diseases $(\text { ERSDs })^{1}(1)$, which affect a variety of organ systems and represent a large group of hereditary and acquired diatheses including subsets of patients with alpha 1-antitrypsin deficiency

G. Medeiros-Neto and P.S. Kim contributed equally to this work. The order of their names is therefore arbitrary.

Address correspondence to Dr. Peter Arvan, Division of Endocrinology, Albert Einstein College of Medicine, 1300 Morris Park Avenue, Belfer 700, Bronx, NY 10461. (Phone: 718-430-2908; FAX: 718-430-8557.)

Received for publication 30 July 1996 and accepted in revised form 8 October 1996.

J. Clin. Invest.

(C) The American Society for Clinical Investigation, Inc. 0021-9738/96/12/2838/07 \$2.00

Volume 98, Number 12, December 1996, 2838-2844
(2), osteogenesis imperfecta (3), diabetes insipidus (4), a range of bleeding and clotting disorders (5), and familial hypercholesterolemia as well as a number of others. In essentially all cases, ERSDs are disorders affecting the folding of exportable proteins. In each instance, the affected gene product fails to be exported and tends to accumulate within the endoplasmic reticulum (ER). This accumulation of misfolded proteins routinely triggers the "ER unfolded protein response," inducing the selective synthesis of a group of ER molecular chaperones $(6,7)$ which bind to misfolded exportable proteins. The binding of ER chaperones has been implicated in what has come to be known as "ER quality control" (8), a phenomenon in which the release of many mutant secretory proteins is prevented by their retention within the ER. Thus, a disease involving a selective protein secretion defect with intracellular accumulation of that secretory protein, in association with the induction of one or more ER chaperones, meets current diagnostic criteria for an ERSD.

We have been interested in deficient thyroglobulin $(\mathrm{Tg})$ as a cause of congenital goiter, once thought to be unusually rare (9) but now recognized as one of the more common inborn errors leading to congenital hypothyroidism. Patients suffering from this illness-with an estimated prevalence of $\sim 1 / 40,000$ live births - can experience hypothyroid growth retardation, abnormal central nervous system function, and local compression of neck tissues due to an enlarged thyroid mass (10). Normally, thyroid hormone formation occurs by iodination of the thyroid prohormone, $\mathrm{Tg}$; this begins around the time of its secretion into the apical lumen of thyroid follicles $(11,12)$. To accomplish this, Tg monomers must first be synthesized in the ER, where they undergo significant conformational maturation and homodimerization before intracellular transport $(13,14)$.

These events may fail to occur in mice homozygous for the cog allele, linked to the Tg locus (15), which exhibit an autosomal recessive phenotype similar to certain humans with congenital goiter (16). Recent evidence strongly supports earlier suspicions that $\operatorname{cog} / \operatorname{cog}$ mice have a mutation affecting Tg tertiary/quaternary structure $(17,18)$, since a full-length Tg is synthesized that undergoes normal $\mathrm{N}$-linked glycosylation and glucose trimming, but is defective in the monomer folding that leads to homodimer formation (19). Consequently in thyrocytes of these mice, most newly synthesized Tg never arrives in the Golgi complex, and accumulates instead within the ER (19). Interestingly, Tg from $\operatorname{cog} / \operatorname{cog}$ mice is directly bound for

1. Abbreviations used in this paper: $\mathrm{BiP}$, immunoglobulin heavy chain binding protein; ER, endoplasmic reticulum; ERSD, endoplasmic reticulum storage disease; GRP94, endoplasmin; hsp, heat-shock protein; Tg, thyroglobulin; TSH, thyrotropin. 
a sustained period to a subset of ER molecular chaperones (including the hsp 90 homolog, GRP94 [20] and the hsp 70 homolog, BiP [21, 22]), while Tg from normal animals associates only transiently with these chaperones $(19,23,24)$. Moreover, GRP94 and BiP are among a subset of ER chaperones whose levels are specifically increased in the thyrocytes of $\mathrm{cog} / \mathrm{cog}$ mice, establishing that this form of congenital hypothyroid goiter is a newly identified member of the family of ERSDs (19).

In human congenital hypothyroid goiter with deficient $\mathrm{Tg}$, postulated defects have included abnormal mRNA splicing, translation, protein transport, posttranslational modifications, or exocytosis, although the most frequently described morphological phenotype involves an enlarged thyroid gland with minimal $\mathrm{Tg}$ in the follicle lumen, and intracellular $\mathrm{Tg}$ immunopositivity within a distended, vesiculated ER (25-29). This has led us to ask whether a thyroid ERSD similar to that of $\operatorname{cog} / \operatorname{cog}$ mice might occur in humans. With this in mind, we have studied two independent kindreds that exhibit a similar autosomal recessive pattern of inheritance for congenital hypothyroid goiter. Taken together, our studies indicate that, at least for the four patients studied, the molecular pathogenesis of this illness involves a thyroid-specific ERSD nearly indistinguishable from that observed in the $\operatorname{cog} / \operatorname{cog}$ mice.

\section{Methods}

\section{Initial patient characterization}

Kindred N. Studies of the gross patient phenotype, and Tg mRNA, from the two affected children of this consanguineous marriage, have already been reported in detail (30).

Kindred $U$. In this kindred, the parents of the two affected siblings are first cousins. The patients, E.N.U. and E.M.U., both with congenital hypothyroid goiter, have been treated with L-thyroxine for most of their lives, are without detectable neurological impairment, and have successfully completed education (to high school and to 7th grade level, respectively). Both have attained normal stature (178 and $180 \mathrm{~cm}$ ) although both demonstrated continuous goiter growth and developed mild to moderate obesity ( 84 and $94 \mathrm{~kg}$, respectively). When L-thyroxine replacement therapy was withheld for 2-4 wk, TRH administration led to an exaggerated serum TSH response in both patients (peak 26.4 and $47.4 \mu \mathrm{U} / \mathrm{ml}$, respectively). Radioiodine uptake was $69 \%$ at $2 \mathrm{~h}$ and $70 \%$ at $24 \mathrm{~h}$ for E.M.U. and $45 \%$ at $24 \mathrm{~h}$ for E.N.U. Ultrasonographic studies indicated that both had large multinodular goiters (estimated weight, 278 g, E.N.U. at age 18; 212 g, E.M.U. at age 14). Thyroid circulating autoantibodies were negative. Northern blotting of RNA isolated from the goiter tissues was performed with the same probe and methodology as described previously (30), revealing a clear, normal-sized $(8.5 \mathrm{~kb}) \mathrm{Tg}$ hybridization signal. Tg mRNAs from E.N.U. and E.M.U. were also reverse transcribed from established primers, as previously described (30), and each of the cDNA fragments individually amplified by PCR. All fragments exhibited the expected sizes upon agarose gel electrophoresis of the rt-PCR products, indicating the absence of any major deletions within the Tg mRNA spanning from positions 57-8448. Finally, no specific $\mathrm{Tg}$-linked restriction fragment length polymorphisms have thus far been identified from preliminary screening of genomic DNA. These studies clearly establish that the presumptive $\mathrm{Tg}$ mutation in kindred $\mathrm{U}$ is different from that found in kindred $\mathrm{N}$.

\section{Hormones and other reagents}

L-thyroxine, protease inhibitors, and iodoacetamide were from Sigma Chemical Co. (St. Louis, MO). Bovine TSH, used for stimulation testing, was from Organon Pharmaceuticals (Sao Paulo, Brazil). Recombinant endoglycosidase $\mathrm{H}$ was from New England Biolabs (Beverly, MA).

\section{Clinical assays}

Thyroid hormone replacement was discontinued for 2 to $3 \mathrm{wk}$ before subtotal thyroidectomy, such that TSH levels were elevated, ranging from $8.3-13.5 \mu \mathrm{U} / \mathrm{ml}$ in each of the four patients described herein. Thyroid tissue at the time of subtotal thyroidectomy was collected in dry ice and stored in liquid nitrogen; all tissue analysis described in this report is derived from these samples. Immunohistochemical staining of thick tissue sections for Tg employed a rabbit polyclonal anti-Tg (Dako Corp., Santa Barbara, CA) with avidin-biotin-peroxidase secondary amplification (31). Electron microscopic analysis of thin sections was performed after fixation in 1\% formaldehyde and $2.5 \%$ glutaraldehyde and embedding in Epon, and the sections were subsequently stained with uranyl acetate and lead citrate. Serum $\mathrm{Tg}$ measured by RIA (Diagnostic Products, Los Angeles, CA) was performed as previously described (32). Serum Tg by IRMA employed two monoclonal antibodies recognizing different $\mathrm{Tg}$ binding sites (Dynotest-Tg, Henning-Berlin, Berlin, Germany) with a control range from 11 normal subjects (see Fig. $1 A$ ).

\section{Animals}

At 2 mo of age, untreated $\operatorname{cog} / \operatorname{cog}$ mice (obtained from the Jackson Labs, Bar Harbor, ME) were hypothyroid (serum thyroxine $<1.0 \mu \mathrm{g} /$ dl) compared to the genetically matched background strain $(\sim 4.0 \mu \mathrm{g} /$ dl). To eliminate pituitary stimulation of the thyroid, both sets of animals were treated (12-16 wk) with $1 \mu \mathrm{g} / \mathrm{ml}$ thyroxine in the drinking water. Excised thyroid glands were obtained from euthanatized mice, trimmed of connective tissue, rinsed several times to remove as much albumin and other extracellular serum proteins as possible, and then lysed directly in an SDS-containing buffer, as described previously (19). For analysis by SDS-PAGE and staining with Coomassie blue, samples were first normalized to DNA content.

\section{Endoglycosidase H digestion}

Endoglycosidase $\mathrm{H}$ digestion was performed essentially as described (33), except that whole tissue homogenates were diluted into the digestion buffer.

\section{Antibodies}

For immunoblotting, we employed a purified chicken IgY directed against a synthetic peptide representing the first 15 amino acids of $\mathrm{Tg}$ (19), and an horseradish peroxidase-conjugated anti-chicken-IgY (Sigma Co.) was employed as a secondary. For GRP94 and BiP, we employed rabbit polyclonal antisera directed against synthetic peptides, as previously described (19).

\section{Gel electrophoretic analysis and Tg immunoblotting}

For mouse tissue samples, thyroid homogenates were analyzed by reducing SDS 4-10\%-PAGE and stained with Coomassie blue. For human tissue samples, thyroid homogenates were analyzed either by the same gel system or by straight SDS 6\%-PAGE. Gels were either stained with Coomassie blue and dried by conventional methods, or transferred to nitrocellulose for immunoblotting with enhanced chemiluminescence (ECL; Amersham, Arlington Heights, IL). Both stained gels and immunoblots were analyzed by scanning densitometry.

\section{Results}

Initial evaluation of two kindreds with congenital hypothyroid goiter. All four patients met clinical criteria for the diagnosis of congenital goiter with deficient $\mathrm{Tg}$, based on their history and initial laboratory evaluation (see Methods), which included intraglandular levels of radioimmunoassayable $\mathrm{Tg}$ that on average $(\sim 1 \mathrm{mg} / \mathrm{g}$ tissue $)$ were $\geq 70$-fold lower than normals ( $\sim 80 \mathrm{mg} / \mathrm{g}$ tissue), as well as a diminished response of immunoreactive serum $\operatorname{Tg}(34,32)$ after acute stimulation with bovine TSH (Fig. 1). While the genetic basis for these clinical findings in kindred $U$ remains unidentified (see Methods), kin- 

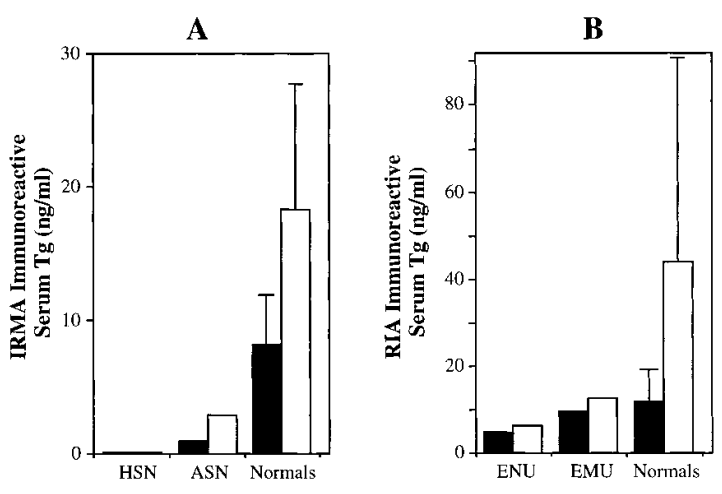

Figure 1. TSH stimulation testing in siblings from two kindreds with congenital hypothyroid goiter. Serum $\mathrm{Tg}$, as detected either by IRMA $(A)$ or by RIA $(B)$, was measured under unstimulated conditions (dark bars) or after stimulation with TSH (open bars). These data are not by themselves unequivocally diagnostic, but in conjunction with additional clinical data (see text), they support the diagnosis of defective $\mathrm{Tg}$ as the cause of congenital hypothyroid goiter in the affected patients.

dred $\mathrm{N}$ exhibits a 138-nucleotide deletion in the Tg mRNA resulting in an in-frame deletion of amino acid residues 1831-1876 (30), which is positioned just proximal to $\mathrm{Tg}$ repeat domain type III a.2 (35). Thus, the predicted $\mathrm{Tg}$ translation product in kindred $\mathrm{N}$ is a mature protein of 2702 amino acids, with a loss of 1 predicted N-linked glycosylation site. Even if this site is used in glycosylation of normal human $\operatorname{Tg}\left(M_{\mathrm{r}} \sim 330,000\right)$ its loss in the mutant would result in the synthesis of Tg with an expected $M_{\mathrm{r}} \sim 323,000$, which would appear indistinguishable from the full-length protein.

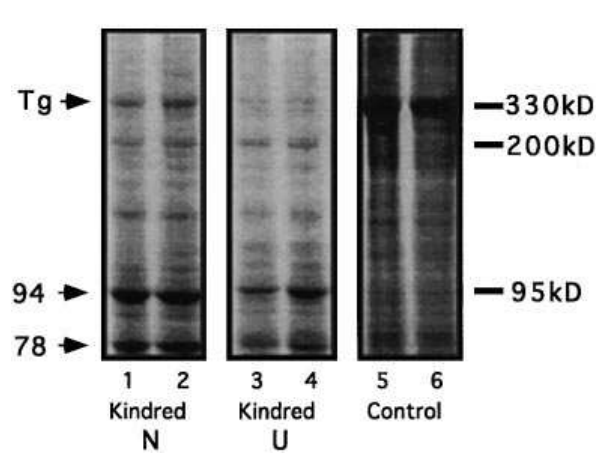

Figure 2. Identification of $\mathrm{Tg}$ and other proteins in thyroid homogenates from affected patients with congenital hypothyroid goiter. Thyroid homogenates from both affected sibs of kindred $\mathrm{N}$ (patients 1 and 2 ) and kindred $U$ (patients 3 and 4 ) were analyzed by reducing SDS-PAGE and stained with Coomassie blue, in comparison to control subjects (samples 5 and 6). The tissues of all individuals are seen to contain stainable $\operatorname{Tg}\left(M_{\mathrm{r}} \sim 330,000\right.$; co-migrating with the position of an authentic, full-length Tg standard, (indicated by arrow at left), although the tissue levels of this protein were substantially inhibited in the affected patients. By contrast, actin, serving as an internal control protein (not shown) was comparable between all samples. Moreover, two prominent Coomassie-stainable bands of $M_{\mathrm{r}} \sim 94,000$ and $\sim 78,000$ were notably increased in the thyroid tissue of affected patients from both kindreds. Independent immunoblotting and immunoprecipitation experiments (not shown) indicated that these two bands do not exhibit Tg immunoreactivity.

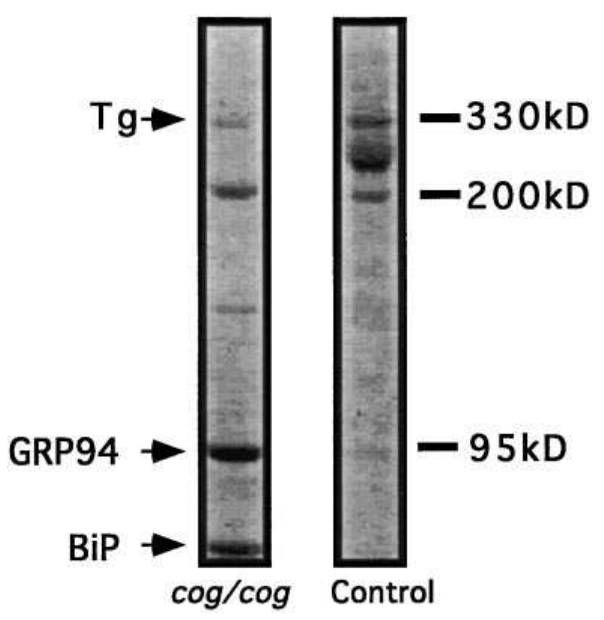

Figure 3. Identification of $\mathrm{Tg}$ and other proteins in thyroid homogenates from $\mathrm{cog} / \mathrm{cog}$ and normal mice. Thyroid homogenates were analyzed similarly to the human tissues described in Fig. 2. Mouse tissues are seen to contain stainable $\mathrm{Tg}$ (the position of a full-length $\mathrm{Tg}$ standard is shown at left). After ER export (24), Tg in normal mice (Con$\mathrm{trol}$ ) is physiologically proteolyzed to generate a $\mathrm{COOH}$-terminal fragment (a darkly staining band of $M_{\mathrm{r}} \sim 250,000$, migrating between the 330 and $200 \mathrm{kD}$ standards), which is essentially undetectable in the mutant $(\mathrm{cog} / \mathrm{cog})$. Independent immunoblotting and immunoprecipitation experiments indicate that the two prominent Coomassiestainable bands of $M_{\mathrm{r}} \sim 94,000$ and $\sim 78,000$, which are notably increased in the mutant thyroid tissue, represent GRP94 and BiP (indicated at left).

Thyroid total protein analysis. We analyzed total proteins contained in thyroid gland homogenates of affected patients and genetically unrelated normal controls by $4-10 \%$ reducing SDS-PAGE, followed by staining with Coomassie blue. As shown in Fig. 2, all four patients exhibited a stainable band of a size representing normal $\mathrm{Tg}$ (immunoreactivity of this band was established, below), although it was diminished in quantity when compared to controls. Thus, at least a portion of the $\mathrm{Tg}$ detected in tissue and sera of these patients derives from a fulllength or near full-length $\mathrm{Tg}$ protein.

As reviewed above, $\operatorname{cog} / \operatorname{cog}$ mice have been described to exhibit a prototypic thyroid ERSD due to abnormal Tg folding and assembly. To further understand the thyroid protein profiles from our patients with congenital hypothyroid goiter, a similar analysis was made from wild type and $\mathrm{cog} / \mathrm{cog}$ mice. As in the human kindreds, thyroid tissue from mutant mice was seen to contain stainable $\mathrm{Tg}$ of a size indistinguishable from normal (Fig. 3). Interestingly, among other Coomassie stainable proteins, two bands in the region of 94 and $78 \mathrm{kD}$, respectively, were selectively increased in the thyroid tissue of mutant mice-recent evidence indicates that these bands are comprised partially or completely of the ER chaperones, GRP94 and BiP (19). Interestingly, when re-examining the gels of our patients and normal human controls, it was noted that all four affected patients showed markedly increased protein bands in the same 94 and $78 \mathrm{kD}$ regions (Fig. 2). Thus, even at this level of analysis, close similarity between the affected patients and the mutant mice was already apparent.

Thyroid histological, immunohistochemical, and electron microscopic analysis. Routine light microscopic examination of thyroid tissue sections demonstrated that in affected pa- 
Kindred

$\mathbf{N}$

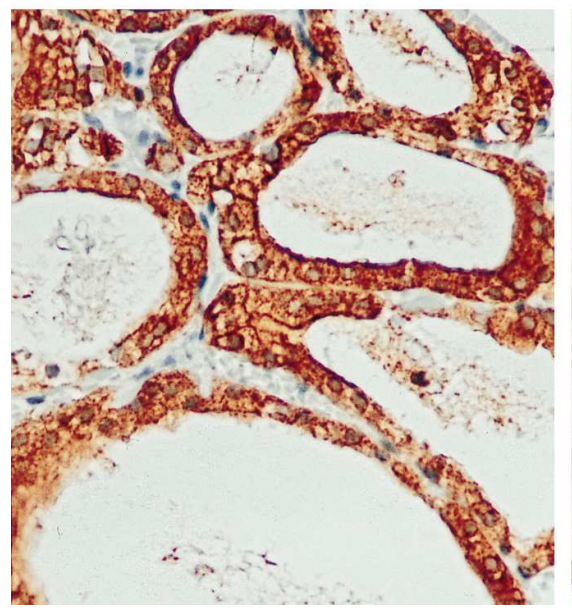

Kindred

$\mathrm{U}$

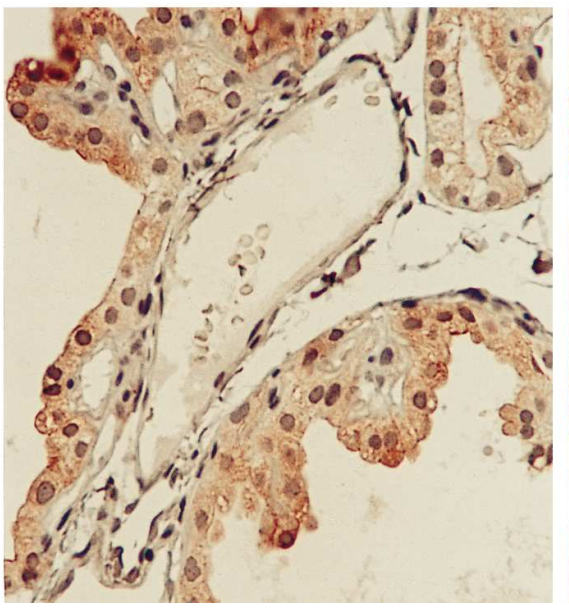

Control

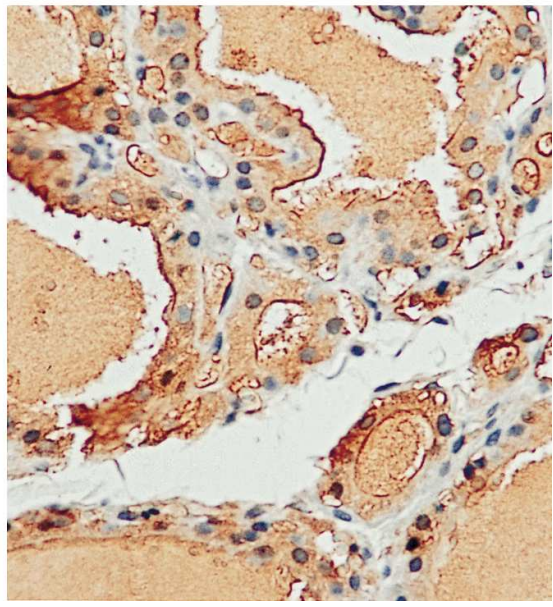

Figure 4. Immunohistochemical localization of Tg. Each thyroid section shows a central region of stromal tissue surrounded by several different follicles cut in profile. The affected patients in kindreds $\mathrm{N}$ (left) and $\mathrm{U}$ (middle) exhibit the relative absence of reaction product in the follicular lumina, with positive reaction product accumulated intracellularly in thyroid epithelial (but not stromal) cells. Note that the small amount of lumenal immunoreaction product in the affected patients was consistent with a low level of thyrocyte shedding into the apical space. By contrast, in control thyroid tissue (right), the $\mathrm{Tg}$ accumulated in the apical lumen of assorted thyroid follicles was intensely immunoreactive.

tients from kindreds $\mathrm{U}$ and $\mathrm{N}$, the follicle lumina were largely devoid of accumulated $\mathrm{Tg}$ protein, as opposed to thyroid tissue from control subjects (not shown). Immunohistochemical localization of $\mathrm{Tg}$ showed a marked decrease of reaction product in the follicular lumina of thyroid sections from affected patients, as compared to a subject without a Tg defect (Fig. 4). Remarkably, however, accumulation of intracellular reaction product was clearly demonstrable in the thyroid epithelium of affected patients (Fig. 4). Thus, the data indicate that immunoreactive $\mathrm{Tg}$ was made in these thyrocytes, although its appearance in the follicle lumen was deficient.

In affected patients, most intrathyroidal thyroglobulin fails to reach the Golgi complex. The preceding findings suggested a disturbance in intracellular Tg transport in our patients with congenital hypothyroid goiter. Normally, upon arrival in the Golgi complex, most but not all of the 15 N-linked carbohydrates on each Tg molecule undergo modification. To establish biochemically whether, in these patients, intracellular Tg ever reaches the Golgi complex, thyroid tissue homogenates were subjected to digestion with endoglycosidase $H$, which cleaves the Tg N-glycans that have not been modified by Golgi processing enzymes (33). By analysis of Coomassie stained SDSpolyacrylamide gels (Fig. $5 \mathrm{~A}$ ), essentially all of the intrathyroidal $M_{\mathrm{r}} \sim 330,000$ band from thyroid homogenates of normal controls appeared resistant to endoglycosidase $\mathrm{H}$ (small mobility shift upon digestion, samples 5 and 6), whereas the same band from affected patients of both kindreds appeared sensitive to endoglycosidase $H$ (larger mobility shift, samples 1-4). To establish that these Coomassie-stainable bands did indeed represent Tg, parallel samples underwent electrophoretic transfer to nitrocellulose for immunoblotting with an antibody prepared against the $\mathrm{Tg} \mathrm{NH}_{2}$ terminus. Indeed, immunoreactive $\mathrm{Tg}$ from affected patients was primarily endoglycosidase H-sensitive (Fig. 5 , left), while Tg from normal controls was primarily resistant to digestion (right). Evidently, Tg mole-

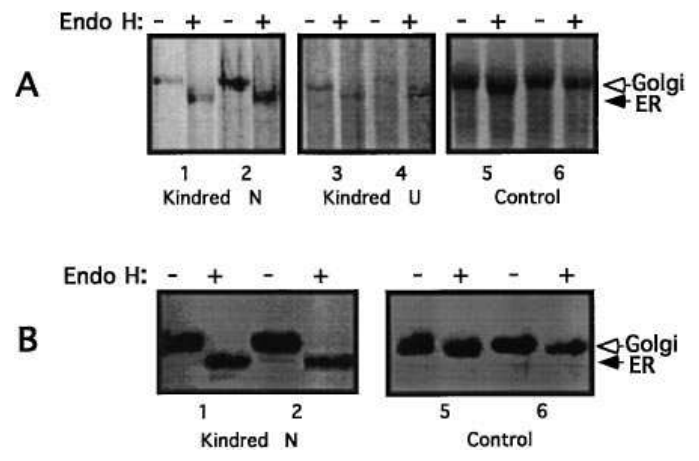

Figure 5. Accumulation of $\mathrm{Tg}$ in the thyroid ER of patients with congenital hypothyoid goiter. $(A)$ To detect the most abundant protein species present in thyroid tissue in the steady state, thyroid homogenates from the patients shown in Fig. 1, normalized to cellular DNA, were digested with endoglycosidase $\mathrm{H}$, analyzed by reducing $4 \%$ SDS-PAGE, and stained with Coomassie blue. A coned-down view of the stainable $330-\mathrm{kD}$ protein is shown. In normal controls, the predominant $\sim 330$-kD protein exists as an endoglycosidase H-resistant (Golgi) form (samples 5 and 6), consistent with storage in a Golgi/ post-Golgi compartment, presumably the extracellular apical lumen. By contrast, in kindreds $\mathrm{N}$ and $\mathrm{U}$ (patients 1-4), diminished (but nevertheless still Coomassie-stainable) quantities of $\sim 330 \mathrm{kD}$ protein appear as an endoglycosidase H-sensitive (ER) form. (B) Thyroid homogenates normalized to similar amounts of $\mathrm{Tg}$ protein, were analyzed as in $(A)$ before transfer to nitrocellulose for immunoblotting with an antibody specifically directed against the extreme $\mathrm{NH}_{2}$ terminus of $\mathrm{Tg}$ (see Methods). Mutant $\mathrm{Tg}$ from kindred $\mathrm{N}$ appears as the endoglycosidase $\mathrm{H}$-sensitive (ER) form (samples 1 and 2), and similar results were obtained in the patients of kindred $U$ (not shown), indicating that the protein has not arrived in the compartment where Golgi-type carbohydrate modifications take place. 
$\mathbf{A}$
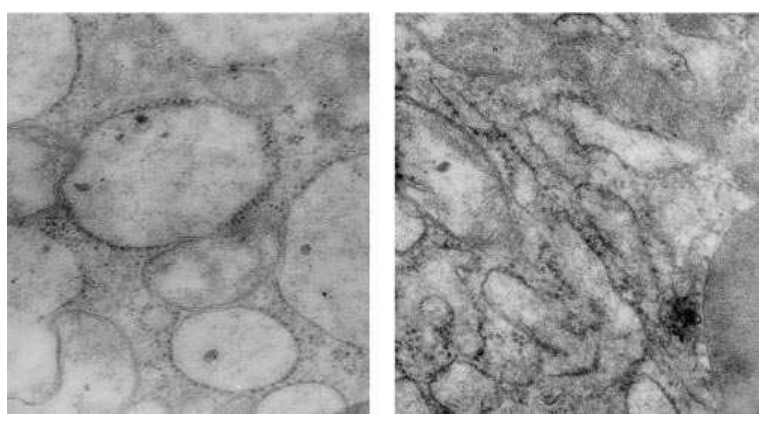

Figure 6. Electron microsopy of thyroid tissue. Equal magnifications of 10,000 from the goiter of an affected patient of kindred $U(A)$ and control thyroid tissue $(B)$. Note the swollen-appearing, ribosomestudded vesicles in the affected patient, which unmistakeably identify the ER. Abundant mitochondria (ribosome-free membranes) were also apparent in both patient and control thyroid tissue. A similarly abnormal appearance was observed in kindred $\mathrm{N}$ (not shown).

cules from the affected patients had not undergone modification of their $\mathrm{N}$-linked glycans, indicating that these molecules never reached the Golgi compartment.

In conjunction with the above studies, electron microscopy was performed on thyroid tissue from these kindreds. Prominent vesicular organelles were observed to be accumulated throughout the cytoplasm in affected patients. As shown for kindred $\mathrm{U}$, these cytoplasmic organelles were identified as ribosome-studded, vesiculated ER (Fig. $6 \mathrm{~A}$ ) - in contrast to the normally more flattened, tubular ER seen at the same magnification from control thyroid tissue (Fig. $6 \mathrm{~B}$ ). Similar ER distention was found upon thyroid electron microscopy of kindred N (not shown), as well as other similar kindreds (25-29). Taken together, the data in Figs. 5 and 6 indicate that in these goitrous patients, $\mathrm{Tg}$ exhibits a specific defect in export from the ER.

Selective elevation of ER chaperones in thyroids of patients with congenital hypothyroid goiter. Among several possibilities, augmentation of protein bands in the region of $M_{\mathrm{r}}$ $\sim 94,000$ and $M_{\mathrm{r}} \sim 78,000$ in the thyroid glands of affected patients (Fig. 2) could represent foreshortened forms of Tg (36), or alternatively, might represent GRP94 and BiP, respectively, two ER chaperones that have been proved to increase an average of approximately eightfold in the thyroid tissue of $\mathrm{cog} / \mathrm{cog}$ mice (19). We note that attempts to pick up these bands upon specific immunoblotting with polyclonal antisera to $\mathrm{Tg}$ were negative (not shown).

We therefore employed immunoblotting with specific chaperone antibodies. Although GRP94 and BiP are already among the two most abundant proteins in the ER of normal cells, (37), when normalized for total cellular DNA, there was a further increase in the expression of these two ER chaperones that was selective to the tissue from the four affected patients (Fig. $7 A$ ). Quantitation of these data suggested that the goiter levels of $\mathrm{BiP}$ were increased 2-4-fold while GRP94 rose 5 -10-fold (Fig. $7 \mathrm{~B}$ ). In toto, the data indicate that the congenital hypothyroid goiter in patients from both kindreds studied, involves an ERSD nearly indistinguishable from that recently reported for $\operatorname{cog} / \operatorname{cog}$ mice (19).
A

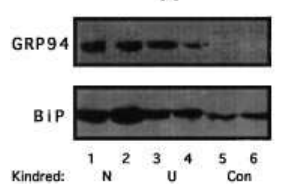

B

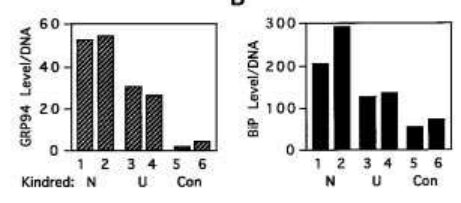

Figure 7. Induction of the molecular chaperones GRP94 and BiP/ GRP78 in thyrocytes from affected patients in kindreds $\mathrm{N}$ and $\mathrm{U}$. Thyroid homogenates, normalized to DNA, were resolved by SDSPAGE under reducing conditions, before transfer to nitrocellulose. Immunoblots using affinity-purified anti-BiP or anti-GRP94 are shown in $(A)$. Quantitation by scanning densitometry $(B)$, revealed significant increases in the levels of both chaperones in thyroids of the affected patients when compared to controls, similar to the chaperone induction reported in the thyroids of $\operatorname{cog} / \operatorname{cog}$ mice (19).

\section{Discussion}

Recent studies exploring the molecular and cell biology of the endoplasmic reticulum have converged with the identification of ERSDs as significant clinical entities. The primary observations are summarized in the following paragraphs. In the overall protein secretion pathway, the ER is now understood as a protein folding compartment. Because the kinetics of folding and assembly of native oligomeric proteins in vivo generally occurs within a rapid timescale, it has seemed plausible that ER resident chaperones such as BiP and GRP94 could, in effect, act as folding catalysts (38). However, unlike true ER foldases $(39,40)$, these two chaperones appear mostly to prevent protein aggregation and other nonproductive folding pathways, a function that is especially important within a compartment where concentrations of unfolded proteins are exceptionally high (41). Thus, while the complete absence of certain ER chaperones (e.g., in genetic knockout experiments) may be incompatible with cell viability (42), there is nevertheless little evidence that these chaperones actually accelerate folding. For that matter, it has actually been difficult to obtain unequivocal evidence that ER residents (other than protein disulfide isomerase) can increase the efficiency of secretory protein folding $(23,43-45) .^{2}$ So why do normal cells of the body have these multiple different chaperones in the ER (19)?

When considering this question, it must be acknowledged that protein folding/assembly in the secretory pathway directs not only the unique biological activity for which each exportable protein is evolutionarily designed, but also is required for the acquisition of transport competence, allowing the protein to advance to the intracellular destination where the primary activity is engaged. ER chaperones like GRP94 and BiP appear to play a major role in the acquisition of transport competence, for which there are currently two possible mechanisms. One theory is that unfolded proteins in the ER might be biophysically unable to advance through the secretory pathway (i.e., due to insolubility) (46); in this case, GRP94 and BiP might assist protein folding and solvation $(47,48)$ to a point where such advance is possible. Alternatively, the mere act of associating with binding proteins such as GRP94 or BiP, which themselves are largely anchored within the ER (49), may serve to prevent export of secretory proteins-part of the process

2. Muresan, Z., and P. Arvan. Manuscript submitted for publication. 
known as ER quality control (8). Indeed, independent elevation of the level of either GRP94 or BiP is, in and of itself, sufficient to prolong the ER residence time for nonmutant secretory proteins (44) including $\mathrm{Tg}$, implicating these specific chaperones as important factors for retaining exportable proteins. Thus, according to the quality control model, a central feature required for secretory protein export is the escape from association with ER chaperones.

Importantly, evidence suggests that during progression through different stages of the folding of exportable proteins, ER chaperones such as BiP (22) go through successive cycles of binding and release. Individual domains of exportable proteins may take advantage of these brief periods of chaperone dissociation to bury potential binding sites; in this view, burying all such potential sites is the culmination of the process of successful protein folding and assembly $(23 ; 19))^{2}$ Thus, it is not difficult to understand how small mutations in secretory proteins like Tg can lead to an ERSD such as occurs in our patients with congenital hypothyroid goiter. Newly synthesized $\mathrm{Tg}$ associates with many copies of BiP and GRP94 en route to homodimerization, during which time, the number of interacting BiP and GRP94 molecules normally declines progressively to zero $(19,23){ }^{2}$ However, Tg mutants may have defects in their ability to bury potential chaperone binding sites. Consequently, although chaperones might dissociate normally from newly synthesized Tg mutants, these binding proteins would tend to re-associate with the defective region in a cyclical fashion. By spending an increased fraction of time bound to chaperones like GRP94 and BiP, the opportunity for Tg to be exported from the ER is diminished, leading to its accumulation in this compartment (Figs. 5 and 6).

Accumulation of misfolded proteins in the ER induces the synthesis of ER chaperones to augmented levels $(6,7)$, and this occurs in the affected patients described herein (Figs. 2 and 7). Using this feedback mechanism, cells maintain a chaperone reserve for further binding to unfolded/misfolded proteins that enter the ER, thereby increasing retention capacity and swelling the ER compartment (19). Consequently, it appears that the ER quality control mechanism itself may contribute as much to the pathogenesis of ERSDs as the original mutation or other insults that interfere with the folding of exportable proteins $(8 ; 19)$. Moreover, to survive the original insult, misfolded proteins in the ER ultimately must be degraded (50) by mechanisms that are as yet poorly understood (51-54). Thus, it is not surprising that despite the accumulation of mutant $\mathrm{Tg}$ in the ER, intraglandular Tg levels in patients with deficient $\mathrm{Tg}$ are actually well below normal (Fig. 2).

Because Tg homodimerization normally occurs before ER export, Tg mutations causing congenital goiter are likely to result in the least efficient dimerization when both monomers are mutant. The autosomal recessive pattern of inheritance in congenital hypothyroid goiter (10) suggests that in most cases, the mutant allele is a passive bystander that does not interfere with the conformational maturation of wild-type $\mathrm{Tg}$. Because $\mathrm{Tg}$ synthesis normally exceeds that needed to maintain thyroid hormone levels from day to day [the excess Tg being stored in the follicle lumina], a much larger population of heterozygotes expressing deficient $\mathrm{Tg}$ presumably remains clinically silent, although such individuals may be predisposed to various forms of goiter (55).

Based upon the precise location within the coding sequence, different mutations in $\mathrm{Tg}$ may result in molecules that advance to different intermediate stages before further folding becomes rate limiting; thus, many mutant Tgs may never achieve homodimerization, which is a kinetically late event (13). In $\operatorname{cog} / \operatorname{cog}$ mice (the only animal model of congenital hypothyroidism in which the $\mathrm{Tg}$ folding pathway has been mapped), the fraction of $\mathrm{Tg}$ which reaches the point of homodimerization or exit from the ER is at the lower limits of detection, while interactions with GRP94 and BiP appear to be protracted indefinitely (19). This is not unlike the sustained accumulation of unassembled immunoglobulin chains in association with BiP (21) and GRP94 (56) in myeloma cells, or the sustained association of $\Delta$ F508 mutant CFTR with calnexin (57) in cells expressing this form of the cystic fibrosis chloride channel. Investigative attempts are actively in progress to identify the specific mutation(s) in Tg from $\operatorname{cog} / \operatorname{cog}$ mice and the human kindred $\mathrm{U}$, while the affected patients in kindred $\mathrm{N}$ are already known to express $\mathrm{Tg}$ with a minor in-frame coding sequence deletion (30). Further work is still needed to know if the various genetic defects in Tg leading to congenital hypothyroid goiter tend to cluster in any particular region of this 2750 amino acid molecule. Nevertheless, congenital hypothyroid goiter with deficient Tg must now be considered a prototypic ERSD, one of a series of illnesses classified not by the organ system(s) affected, but by the underlying cell biological principles that bring about the illness.

\section{Acknowledgments}

This work was supported National Institutes of Health grants DK40344 (to P. Arvan) and DK-02113 (to P. Kim), a grant from Boots Pharmaceuticals (to P. Kim), and grants from FAPESP 94/0917-9 and Klabin Irmåos, Sao Paulo, Brazil (to G. Medeiros-Neto).

We gratefully acknowledge Maria Suzette Pott for secretarial work, and Dr. M. Knobel and Dr. C.L.S. Santos for helpful discussions.

\section{References}

1. Callea, F., M. Brisgotti, G. Fabbretti, F. Bonino, and V.J. Desmet. 1992. Hepatic endoplasmic reticulum storage diseases. Liver. 12:357-362.

2. Sifers, R.N., M.J. Finegold, and S.L. Woo. 1992. Molecular biology and genetics of alpha1-antitrypsin deficiency. Semin. Liver Dis. 12:301-310.

3. Bonadio, J., and P.H. Byers. 1985. Subtle structural alterations in the chains of type I procollagen produce osteogenesis imperfecta type II. Nature (Lond.). 316:363-366.

4. Schmale, H., U. Bahnsen, and D. Richter. 1993. Structure and expression of the vasopressin precursor gene in central diabetes insipidus. Ann. NY Acad. Sci. 689:74-82.

5. Miura, O., Y. Sugahara, and N. Aoki. 1993. Intracellular transport-deficient mutants causing hereditary deficiencies of factors in coagulation and fibrinolysis. Thromb. Haemostasis. 69:296-297.

6. Cox, J.S., C.E. Shamu, and P. Walter. 1993. Transcriptional induction of genes encoding endoplasmic reticulum resident proteins requires a transmembrane protein kinase. Cell. 73:1197-1206.

7. Mori, K., W. Ma, M.J. Gething, and J. Sambrook. 1993. A transmembrane protein with a cdc2+/CDC28-related kinase activity is required for signaling from the ER to the nucleus. Cell. 74:743-756.

8. Hammond, C., and A. Helenius. 1995. Quality control in the secretory pathway. Curr. Opin. Cell Biol. 7:523-529.

9. Dumont, J.E., G. Vassart, and S. Refetoff. 1989. Thyroid disorders. In The Metabolic Basis of Inherited Disease. C.R. Scrier, A.L. Beaudet, W.L. Sly, D. Valle, editors. McGraw-Hill, New York 1843-1883.

10. Medeiros-Neto, G., H.M. Targovnik, and G. Vassart. 1993. Defective thyroglobulin synthesis and secretion causing goiter and hypothyroidism. Endocrine Reviews. 14:165-183.

11. Dunn, J.T. 1992. Thyroglobulin: chemistry and biosynthesis. In Werner and Ingbar's: The Thyroid. L. Braverman and R. Utiger, editors. Lippincott, PA. 98-110.

12. Kuliawat, R., and P. Arvan. 1994. Iodination of thyroglobulin leads to thyroid hormone synthesis and basolateral secretion from filter-polarized thyroid epithelial cells. J. Biol. Chem. 269:4922-4927. 
13. Kim, P.S., and P. Arvan. 1991. Folding and assembly of newly synthesized thyroglobulin occurs in a pre-Golgi compartment. J. Biol. Chem. 266: 12412-12418.

14. Kim, P.S., K.-R. Kim, and P. Arvan. 1993. Disulfide-linked aggregation of thyroglobulin normally occurs during nascent protein folding. Am. J. Physiol. (Cell Physiol.) 265:C704-C711.

15. Taylor, B.A., and L. Rowe. 1987. The congenital goiter mutation is linked to the thyroglobulin gene in the mouse. Proc. Natl. Acad. Sci. USA. 84: 1986-1990.

16. Beamer, W.G., L.J. Maltais, M.H. DeBaets, and E.M. Eicher. 1987. Inherited congenital goiter in mice. Endocrinology. 120:838-840.

17. Basche, M., W.G. Beamer, and A.B. Schneider. 1989. Abnormal properties of thyroglobulin in mice with inherited congenital goiter $(\operatorname{cog} / \operatorname{cog})$. Endocrinology. 124:1822-1829.

18. Fogelfeld, L., G. Harel, W.G. Beamer, and A.B. Schneider. 1992. Lowmolecular-weight iodoproteins in the congenital goiters of $\operatorname{cog} / \operatorname{cog}$ mice. Thyroid. 2:329-335.

19. Kim, P.S., O.-Y. Kwon, and P. Arvan. 1996. An endoplasmic reticulum storage disease causing congenital goiter with hypothyroidism. J. Cell Biol. 133: $517-527$

20. Qu, D., R.A. Mazzarella, and M. Green. 1994. Analysis of the structure and synthesis of GRP94, an abundant stress protein of the endoplasmic reticulum. DNA Cell Biol. 13:117-124.

21. Bole, D.G., L.M. Hendershot, and J.F. Kearney. 1986. Posttranslational association of immunoglobulin heavy chain binding protein with nascent heavy chains in nonsecreting hybridomas. J. Cell Biol. 102:1558-1566.

22. Knittler, M.R., and I.G. Haas. 1992. Interaction of BiP with immunoglobulin light chain molecules: cycles of sequential binding and release. $E M B O$ (Eur. Mol. Biol. Organ.) J. 11:1573-1581.

23. Kim, P., D. Bole, and P. Arvan. 1992. Transient aggregation of nascent thyroglobulin in the endoplasmic reticulum: relationship to the molecular chaperone, BiP. J. Cell Biol. 118:541-549.

24. Kim, P.S., and P. Arvan. 1995. Calnexin and BiP act as sequential molecular chaperones during thyroglobulin folding in the endoplasmic reticulum. J. Cell Biol. 128:29-38.

25. Michel-Bechet, M., G. Cotte, J.-L. Codaccioni, and A.-M. AthouelHaon. 1969. Ultrastructure thyroidienne et perturbations biochimiques de l'hormonogenese. Acta Anat. 73:389-409.

26. Lissitzky, S., J. Torresani, G.N. Burrow, S. Bouchilloux, and O. Chabaud. 1975. Defective thyroglobulin export as a cause of congenital goiter. Clin. Endocrinol. 4:363-392.

27. Cabrer, B., H. Brocas, A. Perez-Castillo, V. Pohl, J.J. Navas, H. Targovnik, J.A. Centenera, and G. Vassart. 1986. Normal level of thyroglobulin messenger ribonucleic acid in a human congenital goiter with thyroglobulin deficiency. J. Clin. Endocrinol. Metab. 63:931-940.

28. Medeiros-Neto, G., H. Targovnik, M. Knobel, F. Propato, V. Varela, M. Alkmin, S. Barbosa, and B.L. Wajchenberg. 1989. Qualitative and quantitative defects of thyroglobulin resulting in congenital goiter. Absence of gross gene deletion of coding sequences in the TG gene structure. J. Endocrinol. Invest. 12: 805-813.

29. Ohyama, Y., T. Hosoya, T. Kameya, N. Suzuki, S. Nakamura, K. Kazahari, K. Shibayama, Y. Yokota, and N. Matsura. 1994. Congenital euthyroid goitre with impaired thyroglobulin transport. Clin. Endocrinol. 41:129-135.

30. Targovnick, H.M., J. Vono, E.C. Billerbeck, G.E. Cerrone, V. Varela, F. Mendive, B.L. Wajchenberg, and G. Medeiros-Neto. 1995. A 138-nucleotide deletion in the thyroglobulin ribonucleic acid messenger in a congenital goiter with defective thyroglobulin synthesis. J. Clin. Endocrinol. Metab. 80:33563360.

31. Matos, P.S., H. Bisi, and G. Medeiros-Neto. 1994. Dyshormonogenetic goiter: a morphological and immunohistochemical study. Endocrinol. Pathol. 5: $49-58$.

32. Leite, Z., P. Carneiro, A. Halpern, and G. Medeiros-Neto. 1987. Reduced serum thyroglobulin response to bovine TSH in malignant hypofunctioning solid thyroid nodules: comparison to benign nodular disease. J. Endocrinol. Invest. 10:255-259.

33. Arvan, P., and J. Lee. 1991. Regulated and constitutive proteins targeting can be distinguished by secretory polarity in thyroid epithelial cells. J. Cell Biol. 112:365-376.

34. Medeiros-Neto, G.A., J.A. Marcondes, H. Cavaliere, B.L. Wajchenberg, and M. Knobel. 1985. Serum thyroglobulin (Tg) stimulation with bovine
TSH: a useful test for diagnosis of congenital goitrous hypothyroidism due to defective Tg synthesis. Acta Endocrinol. 110:61-65.

35. Malthiery, Y., C. Marriq, J.-L. Berge-Lefranc, J.-L. Franc, M. Henry, P.J. Lejeune, J. Ruf, and S. Lissitzky. 1989. Thyroglobulin structure and function: recent advances. Biochimie. Physiol. Pflanz. (BPP). 71:195-210.

36. Ricketts, M.H., M.J. Simons, J. Parma, L. Mercken, Q. Dong, and G. Vassart. 1987. A nonsense mutation causes hereditary goitre in the Afrikander cattle and unmasks alternative splicing of thyroglobulin transcripts. Proc. Natl. Acad. Sci. USA. 84:3181-3184.

37. Marquardt, T., D.N. Hebert, and A. Helenius. 1993. Post-translational folding of influenza hemagglutinin in isolated endoplasmic reticulum-derived microsomes. J. Biol. Chem. 268:19618-19625.

38. Rothman, J.E. 1989. Polypeptide chain binding proteins: catalysts of protein folding and related processes in cells. Cell. 59:591-601.

39. Lodish, H.F., and N. Kong. 1991. Cyclosporin A inhibits an initial step in folding of transferrin within the endoplasmic reticulum. J. Biol. Chem. 266: 14835-14838.

40. Weissman, J.S., and P.S. Kim. 1993. Efficient catalysis of disulphide bond rearrangements by protein disulfide isomerase. Nature (Lond.). 365:185188

41. Helenius, A., T. Marquardt, and I. Braakman. 1992. The endoplasmic reticulum as a protein folding compartment. Trends Cell Biol. 2:227-231.

42. Vogel, J.P., L.M. Misra, and M.D. Rose. 1990. Loss of BiP/GRP78 function blocks translocation of secretory proteins in yeast. J. Cell Biol. 110:18851895 .

43. Dorner, A.J., M.G. Krane, and R.J. Kaufman. 1988. Reduction of endogenous GRP78 levels improves secretion of a heterologous protine in $\mathrm{CHO}$ cells. Mol. Cell Biol. 8:4063-4070.

44. Dorner, A.J., L.C. Wasley, and R.J. Kaufman. 1992. Overexpression of GRP78 mitigates induction of glucose regulated proteins and blocks secretion of selective proteins in Chinese hamster ovary cells. EMBO (Eur. Mol. Biol. Organ.) J. 11:1563-1571.

45. Zapun, A., T.E. Creighton, P.J. Rowling, and R.B. Freedman. 1992 Folding in vitro of bovine pancreatic trypsin inhibitor in the presence of proteins of the endoplasmic reticulum. Proteins. 14:10-15.

46. Pfeffer, S.R., and J.E. Rothman. 1987. Biosynthetic protein transport and sorting by the endoplasmic reticulum and Golgi. Annu. Rev. Biochem. 56: 829-852.

47. Gething, M.-J., and J. Sambrook. 1992. Protein folding in the cell. $\mathrm{Na}$ ture (Lond.). 355:33-45.

48. Simons, J.F., S. Ferro-Novick, M.D. Rose, and A. Helenius. 1995. BiP/ Kar2p serves as a molecular chaperone during carboxypeptidase $\mathrm{Y}$ folding in yeast. J. Cell Biol. 130:41-49.

49. Booth, C., and G.L.E. Koch. 1989. Perturbation of cellular calcium induces secretion of luminal ER proteins. Cell. 59:729-737.

50. Bonifacino, J.S., and J. Lippincott-Schwartz. 1991. Degradation of proteins within the endoplasmic reticulum. Curr. Opin. Cell Biol. 3:592-600.

51. Jensen, T.J., M.A. Loo, S. Pind, D.B. Williams, A.L. Goldberg, and J.R. Riordan. 1995. Multiple proteolytic systems, including the proteasome, contribute to CFTR processing. Cell. 83:129-135.

52. Ward, C.L., S. Omura, and R.R. Kopito. 1995. Degradation of CFTR by the ubiquitin-proteasome pathway. Cell. 83:121-127.

53. McCracken, A.A., and J.L. Brodsky. 1996. Assembly of ER-associated protein degradation in vitro: dependence on cytosol, calnexin, and ATP. J. Cell Biol. 132:291-298.

54. Wiertz, E.J.H.J., T.R. Jones, L. Sun, M. Bogyo, H.J. Geuze, and H.L. Ploegh. 1996. The human cytomegalovirus US11 gene product dislocates MHC class I heavy chains from the endoplasmic reticulum to the cytosol. Cell. 84:769779.

55. Yoshida, S., T.J., K. Kuma, Y. Murakami, S. Sakane, S. Katayama, O. Tarutani, and N. Ohsawa. 1996. A variant of adenomatous goiter with characteristic histology and possible hereditary thyroglobulin abnormality. J. Clin. Endocrinol. Metab. 81:1961-1966.

56. Melnick, J., S. Aviel, and Y. Argon. 1992. The endoplasmic reticulum stress protein GRP94, in addition to BiP, associates with unassembled immunoglobulin chains. J. Biol. Chem. 267:21303-21306.

57. Pind, S., J.R. Riordan, and D.B. Williams. 1994. Participation of the endoplasmic reticulum chaperone calnexin (p88, IP90) in the biogenesis of the cystic fibrosis transmembrane conductance regulator. J. Biol. Chem. 269:1278412788. 